always appears to be larger than does the patella of the other limb. In instances where the fragments are widely separated it is better, as soon as the skin has recovered from the trauma, to remove the fragments of the patella rather than to attempt to fix them together. Such a task must be very difficult, and at the best the result will be a joint which is very sensitive and liable to swell upon even the slightest of injuries or over-use.

\section{Compound Fractures}

These are fortunately very rare, but are seen in motorcar or street accidents. In such cases the treatment of the fracture is of secondary importance, and attention must be directed to preventing the knee-joint becoming infected. As soon as possible, under an anaesthetic, the wound must be cleaned and any dirt or fragments of bone sticking out of the wound removed. It may be necessary to enlarge the skin wound to enable this to be done. The joint if widely opened must be washed out, but no attempt must be made to repair the damage to the capsule or patella. The surfaces of the wound may be approximated with salmon-gut sutures but not closed tightly, so that any serum which may collect can drain into the dressing and not collect under tension in the joint. The limb must be fixed in a Thomas splint, with skin extension applied to the leg. The dressing should be changed every day, and the stitches removed if any sign of infection appears. Should the joint become infected it will require treatment as for any other acute infective arthritis. When the joint has recovered from the risk of infection and the skin has completely cleared up, the fractured patella will receive the appropriate treatment.

\section{Injuries Related to Fracture of Patella}

There are two injuries very closely related to fractures of the patella which require consideration.

Rupture of the Quadriceps Tendon.-This is usually a complete transverse tear, and in nearly every instance if not treated surgically results in a very weak limb. The operative treatment is simple. Through a transverse incision directly over the site of the tear the damaged tendon, with its expansions, is sutured with interrupted catgut. This does not take very long, and the aftertreatment is similar to that used in those cases where the patella has been removed. If the rupture is only partial, conservative treatment will give a satisfactory result.

Rupture of the Patellar Tendon.-This is a very rare accident. If the tear is only partial the limb should be fixed in full extension in plaster for six weeks and the patient permitted to get about on crutches. After removal of the plaster active movements may start and, provided full voluntary extension is maintained, flexion may continue to be increased. If, however, the tendon has been completely torn off the lower hole of the patella, conservative treatment will not be sufficient. The patella is pulled up to a higher level by the quadriceps, while the tendon itself contracts. In these circumstances the site of the injury must be explored and the damage repaired. There is little tissue left on the patella to which to suture the tendon back, and it is therefore necessary to use a fascial graft to repair the damage. The lower part of the patella is drilled transversely so that the graft can be threaded through. It is then sutured to the tendon whilst the patella is held by a sharp hook. The limb must be fixed in plaster for six weeks, after which time the quadriceps must be toned up and active movements of flexion begun. Full function will not be restored for four to six months.

\section{Traumatic Dislocation of Patella}

This injury is a very rare one. It is always an outward dislocation. The patient is found in acute pain, with the knee held in a position of flexion at about 45 degrees. It may be that some friend has pulled the limb straight and the dislocation has been reduced before medical aid is sought. If the dislocation is seen soon after it has taken place it may be reduced without an anaesthetic. The limb should be held as straight as possible and, with one hand made into a fist placed behind the knee, the patient is instructed to try to press the knee against the hand. This will result in a relaxation of the hamstring muscles, and quite light pressure upon the outer border of the patella will enable it to be lifted forwards, when it will at once slip back into position. If this cannot be done, or if the patient is very nervous, the dislocation may be reduced under gas. Subsequent treatment deals with the traumatic synovitis which results. A pressure pad and bandage are applied to prevent the collection of fluid in the joint, and treatment given to the quadriceps. The joint will lack strength and be sensitive to stress for perhaps a week or two, so that it may swell up. Traumatic dislocation of the patella seldom recurs, and in this respect is essentially different from the habitual or recurrent dislocation which is due to an anatomical abnormality.

\section{THE USE OF RADIUM IN WAR-TIME WITH APPENDIX ON RADIUM POISONING BY}

\author{
L. H. GRAY, M.A., Ph.D. \\ AND
}

\section{J. READ, B.Sc., Ph.D.}

\section{RADIUM UNDER WAR-TIME CONDITIONS}

In response to inquiries concerning the necessity or otherwise for rendering radium permanently out of commission under war-time conditions, we submit the following statement of the position as it seems to us.

\section{The Danger Inherent in Use of Radium in War Time}

The danger to life lies in the possibility that through a direct hit by high explosive on a building in which the radium is in use the radium containers might be broken and the naked radium liberated, since radium element which has entered the body is only slowly eliminated and may produce severe injuries and ultimately death. ${ }^{1}$ If naked radium is lying about in the open air there will be serious risk that some will be breathed as radium dust. Even in a laboratory where radium is handled under comparatively carefully controlled conditions it is possible to detect radium dust in a sample of the air in the room. Further, the amount of radium which is lethal when fixed in the body is definitely known to be extremely small-namely, about one-millionth of a gramme. ${ }^{1}$ Thus the complete destruction of a ward in which $500 \mathrm{mg}$. of radium was in use on a number of patients might liberate many thousand lethal doses of radium.

It is difficult to find data on which to base an estimate of the proportion of the radium breathed which becomes fixed in the body. By experiments with animals it has been found that of the radium which enters the blood stream 50 per cent. is

${ }^{1}$ See Appendix, " Radium Poisoning." 
fairly rapidly eliminated; but about 4 per cent. is still in the system at the end of six months, and 2 per cent. at the end of two years (Rajewsky, 1939). These figures, as might be expected, were found to be subject to wide individual variations. There can therefore scarcely be any doubt that if radium element is to be used under war-time conditions one of the following alternatives must be adopied.

(a) The radium might be used at a site where a direct hit by high explosive is a negligible risk.

(b) The radium might be used in such a form that it could be transferred to the bottom of the "radium well "within, say, five minutes of an air raid warning. Clearly, no interstitial radium treatment could be given in these circumstances. The most convenient form in which the radium could be used would probably be teleradium therapy. Several existing " radium beam" units are already equipped with apparatus for the pneumatic transter of radium from the beam unit to a safe, and it would appear to be a relatively simple matter to arrange that the radium, instead of being returned to the safe, be put into a container and automatically lowered down a shaft, thus completely avoiding exposure of personnel and ensuring that the radium was stored in safety. This could probably be done within two minutes of an air raid warning. Arrangements could probably be made to transfer radium in use in the form of plaques, and perhaps radium in gynaecological use, into an ordinary " radium well" within five minutes of a warning. The difficulty here is essentially one of organization so as to ensure (i) that no radium is overlooked; (ii) that all plaques are taken from patients simultaneously, so as to reduce the time to a minimum; and (iii) that exposure of personnel is avoided. The details of such organization would have to be very carefully worked out, but such procedure does not appear to present any insuperable technical difficulties.

(c) The radium could be used under normal conditions if it were agreed that, should the site be hit while the radium is in use, either the site will be abandoned for all time, or the site wiil be carefully cleared of all debris by suitably protected workers, and the debris, together with a small depth of undisturbed earth, be buried elsewhere. If suitable precautions were taken the task of clearing the debris need not involve danger to personnel. Radium continually gives off the gas radon, which is injurious in quite low concentrations, but it is probable that even if $100 \mathrm{mg}$. of radium were liberated in the space of a single ward the radon concentration would not rise to dangerous levels under open-air conditions. Moreover, the concentration can easily be tested before work is started. The danger of breathing radium dust could be eliminated if the workers wore suitable masks (Leitch, 1935). The average concentration of radium element among the debris would be low compared with that in radium ore. Thus, for example, if one wing of this hospital ${ }^{1}$ were demolished while one gramme of radium was in use the concentration of radium in the debris would only be about one-hundredth of the concentration of radium in the ore mined in the Belgian Congo. It is to be noted, however, that in removing debris contaminated with radium the latter may be encountered in small patches of high concentration in the demolished building, so that adequate precautions against the breathing of the dust would be imperative for those clearing the debris.

(d) The Use of Radon.-Although radon is injurious to health if breathed, it is not likely that the liberation of even as much as 500 millicuries by complete demolition of a building would appreciably add to the loss of life and injury caused by the high explosive itself. The site would not be permanently contaminated. The radiation from radon filtered through $0.5 \mathrm{~mm}$. of platinum is identical with that from radium element of the same degree of filtration. In the case of radon irradiation the intensity of the radiation is high at first and falls away to zero (unless fresh radon is introduced), with a halfvalue period of three and a half days. In all other respects radium or radon may be considered to be identical sources of radiation. The radon plant could be set up either in such a

The Mount Vernon Hospital-a solidly built two-story building with subway. The wing measures about 35 feet by 150 feet. position that the risk of a direct hit is negligible, or in a naturally occurring cave or tunnel or a specially constructed "bomb-proof" chamber.

\section{APPENDIX ON RADIUM POISONING}

Below are listed a number of papers dealing with this subject published during the last ten years. It is evident that during the earlier part of this period the difficulty of measuring minute quantities of radium in a living person, and tiny radon concentrations in the breath, led to much inaccuracy and conflicting results. However, in the work of Rajewsky (1936, 1939 ; Janitzky, Krebs, and Rajewsky, 1938) and Robley D. Evans (1933, 1937; Evans and Aub, 1937 ; Aub, Evans, Gallagher, and Tibbetts, 1937-8) accuracy of measurement has reached a high standard-Evans (1937) can measure down to 0.2 microgramme in a living person-and their results seem reliable and consistent. Among earlier papers a series of four in the American Journal of Industrial Hygiene on conditions in the watch-dial painting industry is notable (Ives, Knowles, and Britten, 1933). From a study of this literature the behaviour of radium after its introduction in the body appears to be as follows.

Most of the radium taken by mouth is rapidly eliminatedabout half in a few days and 90 per cent. in a few weeks. The rate of elimination continually diminishes, however: after six months it is about 0.02 per cent. of the remaining radium per day, after one year 0.004 per cent., and after ten years 0.003 per cent. The amount of radium still in the body after one year can for practical purposes be considered as fixed there. If the radium is taken intravenously the initial rate of elimination is about half as quick, but after a few weeks the rate becomes the same. However, owing to the slower start a given quantity of radium taken intravenously will always show a higher residuum than if it is taken by mouth. Rajewsky (1936) says that about 0.5 to 1 per cent. of radium taken by mouth and from 2 to 5 per cent. of radium taken either intravenously or by breathing becomes fixed in the body. Evans (private communication) has found that the fractional retention of radium taken by mouth is from 1 to 5 per cent., and he believes that for intravenously injected or breathed radium the retention is about 10 per cent.

In the first week or so radium is distributed throughout all the tissues; it then becomes concentrated in bone trabeculae and finally in the bone cortex. However, the concentration is by no means uniform throughout the skeleton. The distribution found by Rajewsky (1936) in a woman poisoned by breathing radium dust, who died three years after her last exposure, is given in the table:

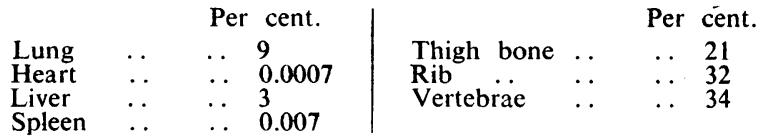

Schlundt and Failla give the following radium concentrations in various bones:

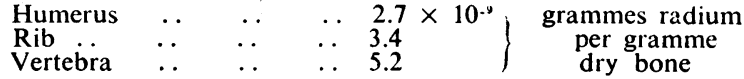

During the early part of the history, radon in the breath is about 50 per cent. of that produced by the radium, but after some years, when the radium is fixed in the bones, this drops to from 3 to 10 per cent. (Rajewsky, 1936). Elimination of radium at this stage is 90 per cent. in the faeces and 10 per cent. in the urine (Evans, 1937).

The fatal dose is usually stated in terms of the residual radium at the time of death. However, as death may be as long as ten years after the radium intake, the actual damage to which death is due may have been caused by the much larger quantities originally present. Evans describes the case of a watch-dial painter who was examined for radium once a year for eight years with negative results, presumably by a crude method. He developed necrosis of the jaw, and just before he died Evans (1937) measured a total content of 1.2 microgrammes. Rajewsky (1936) describes the case of a woman 
whose death resulted from the breathing of radium dust (lung carcinoma) five years after starting employment in a radium laboratory. After her death 6 microgrammes of radium were measured in the body; the lung, which was the site of the immediate cause of death, contained less than 1 microgramme. Several similar cases can be quoted, but in contrast to these are two women described by Evans (1937). The first had intravenous injections of radium chloride ten years back and still contains 8.5 microgrammes. Her weight is $160 \mathrm{lb}$. and height $5 \mathrm{ft} .8 \mathrm{in}$. The second took radium by brush-licking while watch-dial painting during 1922 to 1929, and in 1937 was still so employed, except that a glass pen technique was used. She then contained 9.7 microgrammes, and her weight was $116 \mathrm{lb}$. and her height $5 \mathrm{ft}$. 5 in.

Evidence of harmful effects of radium less serious than death is contained in the American Journal of Industrial Hygiene reports (Ives, Knowles, and Britten, 1933). An investigation was made from June, 1929, to March, 1930, on two groups of watch-dial workers: Group A, seventy persons, all having started work after brush-licking had been abolished on January 1, 1927; Group B had worked before that date. Group A contained persons who had from 0.1 to 2.4 microgrammes of radium due to breathing radium dust. They showed a tendency to a lower red cell and haemoglobin determination than in a group of controls. Bone changes for Groups A and B, classified against radium content of the individuals, are shown in the table:

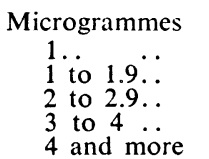$$
\begin{array}{cr}
\multicolumn{2}{c}{\text { Per cent }} \\
\text { bone } & \text { ch } \\
. & 5 \\
\therefore & 12 \\
\therefore & 17 \\
\therefore & 40 \\
. & 100
\end{array}
$$

These measurements were made during exposure to radium intake and within relatively few years of the first exposure, in contradistinction to the earlier cases mentioned, which had all the radium fixed in the skeleton for some years.

According to Martland (1931; McClelland, 1933), for several centuries the underground workers in the cobalt mines of the Schneeberg district and in the pitchblende mines of Joachimsthal have been subject to a pulmonary disease resulting in death in middle life. An official investigation extending over three and a quarter years resulted in a diagnosis of carcinoma of the lungs in 62 per cent. of the deaths among miners. During the same period examination of 362 persons in the same districts, not working in the mines, discovered no indication of malignancy in the lungs. These deaths have been variously ascribed to rock dust, dampness, volatile arsenical compounds, chrome and arsenic dust, but, as the air of the mines is distinctly radio-active and as breathing radium dust in laboratories has been shown to produce lung carcinoma, the radio-activity of the air must be regarded as a likely cause.

From a consideration of these papers it seems probable that, though there is a considerable variation from one person to another, an ingestion of about 500 microgrammes will lead to a fixed quantity of about 5 microgrammes, causing ultimate death. In some cases as little as 50 microgrammes might produce this result. These quantities are roughly halved if radium is taken intravenously; but it is difficult to deduce from this the fatal dose which must be inhaled, as we have no data on what proportion of dust inhaled is retained in the body.

\section{BIBLIOGRAPHY}

Radium Poisoning

Aub, Evans, Gallagher, and Tibbetts (1937-8). Effects of Treatment on Radium and Calcium Metabolism in the Human Body. Ann. intern. Med., 11, 1443.

Report on an attempt to treat three cases of radium poisoning by dietary methods, aimed at increasing the rate of elimination. The three cases of poisoning occurred $(a)$ by deliberate intravenous injection, $(b)$ by brush-licking on the part of an operative in the luminous-watch-dial industry, $(c)$ an explosion in which radium was scattered and some dust particles fell on the face of a physicist and were probably breathed. Detailed case histories, measurement of radium content, and rate of climination are given, but these were begun many years after the radium entered the system in the first two cases and about four weeks after the accident in the third case.
Daels, Fajerman, Van de Putte, and.Van Hove (1938). Question of the Distribution in Various Tissues of Soluble Radium injected into Experimental Animals. Strahlenth., 63, 545. (In German.)

Evans, R. D. (1933). Radium Poisoning, a Review of Present Knowiedge. Amer. J. publ. Hlth., 23, 1017.

Discusses modes of radium poisoning, symptoms, elimination, and distribution of residual radium in the body.

Evans, R. D. (1937). The Quantitative Determination of the Radium Content and Radium Elimination Rate of Living Persons. Amer. J. Roentgen., 37, 368.

Detailed description of apparatus and method of measuring the radium content of living persons and of the technique of measurement. Includes data on three patients, one of whom had received intravenous injections, and two operatives from the luminous-watch-dial industry.

Evans and Aub (1937). Recent Progress in the Study of Radium Poisoning. Cancer Probl. Sympos., p. 227.

Flinn, F. B. (1934). Radium Salts and Emanation. Amer. J. Roentgen., $31,830$.

Discusses effects of drinking radium and radon water, and the breathing of radon. Gives data on the elimination of radon from the body. Discusses the Joachimsthal lung carcinoma.

Janitzky, Krebs, and Rajewsky (1938). On the Problem of Radium Poisoning, II. Strahlenth., 61, 254.

A more detailed account of experimental measurements referred to in the paper by Rajewsky (1939) cited below. (In German.)

Rajewsky (1936). Investigation of the Problem of Radium Poisoning. Strahlenth., 56, 703. (In German.)

Much of the same material as that included in Rajewsky's other papers listed here.

Rajewsky (1939). The Problem of Radium Poisoning and Tolerance Dose. Radiology, 32, 57.

A general review of the subject, giving data obtained in the author's laboratory for the distribution of the radium between various organs and the rate of elimination (mostly from animal experiments). Brief report of two cases of radium poisoning in human subjects.

\section{Radium Hazards in Industry}

Ives, Knowles, and Britten (1933). Health Aspects of Radium Dial Painting: Measurement of Radio-activity in Workers. Amer. J. industr. Hyg., 15, 433.

This paper, together with three others of the same series, gives interesting data on the radio-active content of workers employed in radium dial painting, on the effect on their health, and on the radium dust content of the air breathed.

Kalbfleisch, H. H. (1937). Fatal Fibrosis of the Lungs. Arch. Gewerbepath. Gewerbehyg., 7, 700. (In German.)

Leitch, J. D. (1935). Health Hazards in the Radium Industry. N.R.C. of Canada, Bulletin 16.

A section on "Prophylaxis in Working Conditions" discusses the use of masks and other protective measures in radium mining.

Löwy, J. (1938). Der Bronchialkrebs als Berufskrankheit Acta internationalen Vereinigung Krebsbekainpfung, 3, 182.

McClelland, W. R. (1933). Health Hazards in the Production and Handling of Radium. Ore Dressing and Metallurgical Investigation No. 550 of the Department of Mines, Canada.

Martland, H. (1931). The Occurrence of Malignancy in Radioactive Persons. Amer. J. Cancer, 15.

Discusses the Schneeberg and Joachimsthal lung cancers.

Morris, J. P. (1938). Hazards in the Radium and Mesothorium Refining Plant at the University of Missouri. J. industr. Hyg. 20,36 .

Contains data regarding the amount of laboratory air radium dust under various conditions, and also a series of measurements of the radon and thoron content of the air expired by workers. The plant had been in operation six years at the time of the report.

Teleky, L. (1937). Occupational Cancer of the Lung. J. industr. Hyg., 19, 73.

Tschelnitz, H. (1935). Physikalische Bemerkungen zur Ätiologie des St. Joachimsthaler Lungenkarzinoms. Strahlenth., 53, 269.

** A more complete discussion of radium poisoning, written by Dr. J. Read, will appear shortly in the British Journal of Radiology.

Dislocation of Hip. - - In about 5 per cent. of all patients with congenital dislocation of the hip the deformity is combined with other malformations. In such cases the dislocation of the hip appears to be caused by mechanical factors and should be regarded as a secondary deformity. Twenty-eight illustrative cases are described by the author and the previous literature is reviewed.--Significance of Dislocation of Hip combined with Other Malformations for Problem of Dislocation of Hip.-W. Müller.-Z. Orthop., May 30, 1939, 69, 293. 